\title{
Evaluation of a dental emergency e-learning course for accident and emergency staff Abstract
}

\author{
Arif Razzak $^{1 *}$, Ali al-sharifi ${ }^{2}$, Alex Goodson ${ }^{3}$ and Madhav Kittur ${ }^{4}$ \\ ${ }^{1}$ OMFS, Swansea Morriston Hospital, Swansea, UK \\ ${ }^{2}$ Emergency Medicine, Queen Elizabeth Hospital, Birmingham, UK \\ ${ }^{3} \mathrm{OMFS}$ registrar, Morriston Hospital, UK \\ ${ }^{4}$ OMFS consultant, Morriston hospital, Swansea, UK
}

\begin{abstract}
Introduction: Many patients who attend A\&E services attend with dental issues, and unfortunately many doctors get limited dental teaching. The aim was to create an e-learning course and evaluate its effectiveness via the use of pre- and post- course tests.

Method: 21 A\&E doctors from two trusts (Morriston Hospital and Princess of Wales Hospital) were invited to take part in a pre-test made up of 5 multiple choice questions and were then given an electronic copy of the course, covering 3 main topics (dental trauma, dental abscesses, and post-extraction complications). The doctors were then requested to fill out a post-test questionnaire after completion of the course and return the results. 11 responses were received, and the pre- and post- tests were statistically analyzed.

Results: The average result from a pre-test was 1.95 across the 21 original tests. 10 people did not return the post-test questionnaire. Of the eleven who did, all the post-test results were better than the pre-test results, with an average increase of 2.55 points (maximum mark 5 points), with a p value of $<0.01$. Feedback from the participants stated that the immediate management for two patients was altered within a 6-week period (one A\&E doctor stated that she used tranexamic acid topically to manage a bleeding socket, and another $\mathrm{A} \& \mathrm{E}$ doctor correctly identified that a tooth was not avulsed following a traumatic incident).

Conclusion: The results from this study suggests that A\&E doctors found the course useful, and benefitted from the content, which has had a positive impact on patient care. The course has been submitted to the RCEM (royal college of emergency medicine) with the aim of it becoming available on the RCEM learning website, with doctors being able to claim CPD hours for taking part in the course.
\end{abstract}

\section{Introduction}

In the UK and England, it has been suggested that around $0.7 \%$ of accident and emergency ( $A \& E$ ) attendance is due to dental pain. Unfortunately, patients who attend in this manner are often not assessed by someone who is dentally qualified [1]. Patients may also attend $\mathrm{A} \& \mathrm{E}$ with other dental issues, namely post-operative bleeding following extractions, and with dental trauma (either isolated, or associated with other injuries arising from the trauma). Previous studies have shown that many emergency department senior house offices (SHOs) have limited training and knowledge with dealing with dental issues [2]. Considering that the SHO's questioned in a study by Patel et al reported to see between 1 and 5 dental issues each week, it is some cause of concern that $52 \%$ reported never having any training on examination of the mouth [2].

Medical education can be both time consuming, as well as costly, and dental pathology is likely to rank low on an essential list of information that needs to be implemented by emergency department staff, potentially explaining the lack of training, experience, and confidence in dealing with these cases [3].

Electronic based learning systems are becoming more common and have been shown in various instances to be a cost-effective method of providing teaching $[4,5]$. The authors therefore felt that an e-learning course would be beneficial to effectively distribute training and core information, and so created an e-learning course, and evaluated its effectiveness.

\section{Method}

A questionnaire comprising of 5 questions, in a 5-option multiple choice questionnaire (MCQ) was created and used as an assessment tool for doctors working within two emergency departments across two different trusts (Morriston hospital, Swansea and Princess of Wales Hospital, Bridgend). The topics covered included the diagnosis and management of a bleeding socket, a dry socket, dental trauma and dental abscesses. 21 members of staff agreed to take part in the study.

Volunteers were asked to indicate which answer they felt was correct and were asked to state their role as either a senior, middle or junior grade member of staff. These questionnaires were then collected, and the questionnaires scored. Participants were not given the answers after completion of the questionnaire. After all the results were returned, the volunteers were sent an electronic copy of an e-learning module prior to it being released online in the form of a word document. The

${ }^{\star}$ Correspondence to: Arif Razzak, OMFS, Swansea Morriston Hospital, Swansea, UK, E-mail: arifrazzak@yahoo.com

Received: October 04, 2018; Accepted: October 11, 2018; Published: October 16,2018 
volunteers were then requested to go through the learning resource and repeat the exam without using the course as a reference and return the results of the exam. Participants were also invited to provide feedback on the course in the form of qualitative data, stating what they liked and what they didn't like, and what improvements they could recommend. We received 11 responses to the second test from the original 21 participants.

\section{Course content}

The course has aimed to include 3 areas of dental issues which commonly attend in the emergency department setting: dental pain and abscesses, post-extraction complications (including dry and bleeding sockets), and dental trauma [6,7]. Each section of the course covers the etiology, some definitions, diagnosis and treatment of common issues, and is aimed to be suitable for non-dentally qualified staff to be able to understand, and safely treat patients.

\section{Statistical analysis}

The results were analyzed, noting the questions where marks were lost. A T-test was performed to compare the post-course results against the pre-test results for the individuals who returned both results. An ANOVA test was performed to assess if there was a different in the pretest results based on seniority.

\section{Results}

Of the original 21 individuals questioned, 11 were at a junior level, 7 were middle grade, and three were senior level (Figures 1 and 2). The initial test results had an average result of 1.95 marks out of a possible maximum mark of 5 marks. An ANOVA test showed that there was no statistically significant difference in pre-course test result based on the grade of doctor answering the questions (Figure 3), however there were a limited number of representatives from the senior level doctors.

\begin{tabular}{|c|c|c|c|c|}
\hline Pre-test result & Post-test result & Result difference & Job title & Grade (senior, middle or junior) \\
\hline 2 & & & Junior clinical fellow & Junior \\
\hline 1 & & & Registrar & Middle \\
\hline 2 & 5 & 3 & FY2 & Junior \\
\hline 1 & & & SAS & Middle \\
\hline 2 & 5 & 3 & Registrar & Middle \\
\hline 1 & 3 & 2 & SHO (GPT) & Junior \\
\hline 3 & 5 & 2 & Clinical fellow & Middle \\
\hline 2 & & & FY2 & Junior \\
\hline 1 & 3 & 2 & FY2 & Junior \\
\hline 1 & 5 & 4 & Registrar & Middle \\
\hline 2 & 4 & 2 & Senior clinical fellow & Senior \\
\hline 3 & & & SHO & Junior \\
\hline 2 & & & SHO (GPT) & Junior \\
\hline 2 & & & Consultant & Senior \\
\hline 3 & & & SHO & Junior \\
\hline 3 & 5 & 2 & Clinical fellow & Middle \\
\hline 3 & & & S.A.S & Senior \\
\hline 2 & 5 & 3 & Registrar & Middle \\
\hline 2 & & & FY2 & Junior \\
\hline 3 & 5 & 2 & SHO & Junior \\
\hline 0 & 3 & 3 & & Junior \\
\hline
\end{tabular}

Figure 1. Shows a table of the results. Note that eleven doctors returned their post-course test out of the original twenty-one

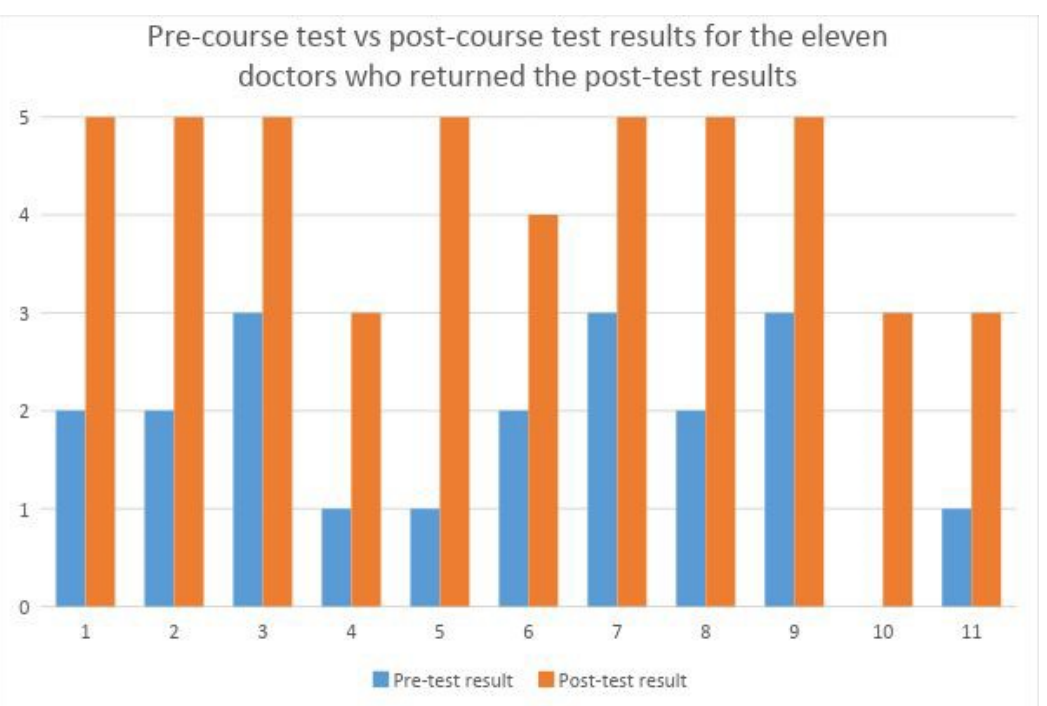

Figure 2. shows the graphs of pre-course results vs post-course results. All doctors taking part in the course had an improvement in their result. The maximum mark was 5 . $\mathrm{P}$ value $<0.001$ 


\begin{tabular}{|c|c|c|c|c|c|c|c|}
\hline Anova: Single Factor & & & & & & & \\
\hline \multicolumn{8}{|l|}{ SUMMARY } \\
\hline Groups & Count & Sum & Average & Variance & $S D$ & Low & High \\
\hline Junior & 11 & 21 & 1.909091 & 0.890909 & 0.94388 & 0.965211 & 2.852971 \\
\hline Middle & 7 & 13 & 1.857143 & 0.809524 & 0.899735 & 0.957407 & 2.756878 \\
\hline Senior & 3 & 7 & 2.333333 & 0.333333 & 0.57735 & 1.755983 & 2.910684 \\
\hline \multicolumn{8}{|l|}{ ANOVA } \\
\hline Source of Variation & SS & $d f$ & $M S$ & $F$ & $P$-value & F crit & \\
\hline Between Groups & 0.519480519 & 2 & 0.25974 & 0.323935 & 0.727427 & 1.762319 & \\
\hline Within Groups & 14.43290043 & 18 & 0.801828 & & & & \\
\hline Total & 14.95238095 & 20 & & & & & \\
\hline
\end{tabular}

Figure 3. shows the calculations for the ANOVA test for the pre-course test results, showing a non-significant $P$ value of 0.727

\begin{tabular}{|l|r|r}
\hline & & \\
\hline & Variable 1 & Variable 2 \\
\hline Mean & 1.818182 & 4.363636 \\
\hline Variance & 0.963636 & 0.854545 \\
\hline Observatic & 11 & 11 \\
\hline Pearson C & 0.741336 & \\
\hline Hypothesi: & 0 & \\
\hline df & 10 & \\
\hline$t$ Stat & -12.2788 & \\
\hline$P(T<=t)$ on & $1.18 E-07$ & \\
\hline$t$ Critical o & 1.812461 & \\
\hline$P(T<=t)$ tw & $2.35 E-07$ & \\
\hline$t$ Critical tv & 2.228139 & \\
\hline
\end{tabular}

Figure 4. shows the $\mathrm{T}$ test statistical analysis for the differences for the results of the pre-test vs the post-test results for the individuals who returned their post-test results, showing a statistically significant $\mathrm{P}$ value of $<0.001$

For the eleven doctors that completed and returned the post-course test, the average pre-test score was 1.81 , with an average post-test score of 4.36. All participants had an improvement in the post-course test result as compared with the pre-test score (average increase 2.55) and was statistically significant with a P value less than 0.001 (Figure 4).

As there was only one post-course test response from someone from a senior level, it was not possible to accurately assess if there was a significant different in score difference between different seniority of doctors.

\section{Qualitative data}

In terms of qualitative data, two out of the eleven emergency department doctors who returned the questionnaire stated that the course had a positive impact on specific patient cases. The first case was a patient who attended the emergency department with a bleeding socket. The doctor in question stated that they had read in the course about applying pressure with a gauze soaked in tranexamic acid, and proceeded to do so, and achieved adequate hemostasis.

The second case involved a patient who had dental trauma, and the patient stated that they had lost a tooth. The doctor stated that he used the information in the dental trauma section of the course to correctly identify that this was not strictly speaking the case, as there was no socket where the tooth had been knocked out (it transpired that the patient had an acid-etch retained bridge that was lost during the incident). Regardless of this, the doctor in question stated that it made the clinical scenario easier to manage, realizing that the situation was not a true tooth avulsion, and was able to communicate this with the patient, and whilst referring the patient to the maxillofacial team (the patient also had a separate zygomatic fracture).

In terms of other qualitative data, one of the emergency doctor registrars stated that the course "met the core curriculum requirements for emergency doctor registrar training", and commented on its usefulness with regards to revision, and provided more clarity on topics that he previously did not fully understand. Another doctor commented that the content of the course aided him in providing a presentation on dental trauma to other colleagues within his department.

Some doctors had stated that they felt the course could include more content and detail, such as how to splint a tooth. The authors of this course felt that splinting of the teeth should be carried out by someone experienced, and in order to appropriately teach splinting, 
online study only may not be appropriate. Instead, we felt a combination of practical teaching as well as theoretical teaching in a supervised environment would be best suited for teaching these skills, and as such felt it unsafe to try to deliver practical teaching in an online course alone. From a clinical perspective, it is the re-implantation time, and not the splinting time that has an impact on tooth prognosis, and so the focus of the course was to education emergency staff, and advising the course to contact the nearby maxillofacial department or other relevant department and to request assistance, rather than to try and manage dental trauma solely in house [8].

\section{Limitations}

Some of the limitations of this study include the fact that we had a relatively small number of participants, with around a 50\% dropout rate. Furthermore, the first questionnaire was done without access to any materials, and although participants were requested to not refer to any materials when doing the post-course questionnaire, it is possible that this did occur (although feedback from the participants was that they did not do this). Furthermore, it is likely that those participants who did respond to the second questionnaire were those who engaged with the course more (and thus also engaged with a repeat test). It seems reasonable to assume that students who engage with the learning material more would benefit most from its use.

\section{Conclusions}

Within the limitations of this study, the authors feel that this course has provided some much-needed training in a cost-effective and time efficient way, that is easily accessible to its target audience. Both the qualitative and quantitative feedback has suggested that this course is providing some benefit to its participants, as well as patients directly (as the authors are aware of two patients who received the appropriate treatment following participation in this course). After completion of this study, we were approached by other members of the emergency departments asking or copies of this course as they had heard form colleagues how it had helped them with the diagnosis and early management of many different dental conditions, with some doctors stating that they had struggled on where to find the appropriate material to use. This would suggest that many emergency care practitioner's feels that this topic is an important one and felt that this course provided a benefit to them.

The learning course is being made available for the RCEM learning website, and the authors would recommend that any practitioners within the emergency dental care setting requiring some more material on management of common dental conditions that can present in their environment to go through the course material themselves.

\section{References}

1. Currie CC, Stone SJ, Connolly J, Durham J (2016) Dental pain in the medical emergency department: a cross-sectional study. J Oral Rehabil 44:105-111. [Crossref]

2. Patel KK, Discoll P (2002) Dental knowledge of accident and emergency senior house officers. Emerg Med J 19: 539-541. [Crossref]

3. Norman G (2010) Medical education: Theory and practice. Dornan T, Mann KV, Albert J. J. A. Scherpbier, editors. Edinburgh: Elsevier Health Sciences.

4. Allen IE, Seaman J (2007) Online nation: Five years of growth in online learning. Sloan Consortium. PO Box 1238, Newburyport, MA 01950.

5. Clark RC, Mayer RE (2003) E-learning and the science of instruction. San Francisco, CA: JosseyBass.

6. Wall T, Nasseh K (2013) Dental-related emergency department visits on the increase in the United States. Health Policy Resources Center Research Brief. Am Dent Assoc.

7. Pennycook A, Makower R, Brewer A, Moulton C, Crawford R (1993) The management of dental problems presenting to an accident and emergency department. $J R$ Soc Med 86: 702-703. [Crossref]

8. Flores MT, Andersson L, Andreasen JO, Bakland LK, Malmgren B, et al. (2007) Guidelines for the management of traumatic dental injuries. II. Avulsion of permanent teeth. Dent Traumatol 23:130-136. [Crossref]

Copyright: (C2018 Razzak A. This is an open-access article distributed under the terms of the Creative Commons Attribution License, which permits unrestricted use, distribution, and reproduction in any medium, provided the original author and source are credited. 